Euskal ikerketen aldizkaria | Revue d'études basques |

Revista de estudios vascos | Basque studies review

Numéro Spécial 1 | 1999

Les lettres basques au temps d'Axular (1600-1650)

\title{
Gero-ren bi parteak
}

Les deux parties du Gero d'Axular

\section{Jean Haritschelhar}

\section{OpenEdition \\ Journals}

Édition électronique

URL : http://journals.openedition.org/lapurdum/1601

DOI : 10.4000/lapurdum.1601

ISSN : 1965-0655

Éditeur

IKER

Édition imprimée

Date de publication : 1 octobre 1999

Pagination : 105-118

ISBN : 2-84127-157-9

ISSN : $1273-3830$

Référence électronique

Jean Haritschelhar, « Gero-ren bi parteak », Lapurdum [Linean], Numéro Spécial 1 | 1999, Sarean emana----an 01 juin 2010, kontsultatu 30 janvier 2020. URL : http://journals.openedition.org/ lapurdum/1601 ; DOI : 10.4000/lapurdum.1601 


\section{Jean HARITSCHELHAR}

\section{GERO-ren BI PARTEAK}

Irakurtzen delarik Gero-ren titulua argi dago bi partetan egina dela : "Guero bi partetan partitua eta berecia... ", bainan "irakurtzailleari” deritzan aitzin solasean dio Axularrek :

"Eta hala deliberatu nuen, buru-eragotzcarri beçala, liburutto baten, bi partetan partituric, guero, hunen gaiñean eguitera.

Eta nahi nituzqueyen bi parteac elccarrequin, eta batetan athera. Baiña icussiric cein gauça guti edireiten den euscaraz esquiribaturic, gogan behartu naiz eta veldurtu, eztiren bideac asco segur eta garbi, baden bitartean, cenbait trabu edo behaztopa harri. Eta halatan hartudut gogo, lehenbicico parte hunen, lehenik venturatçeco, eta berri iaquitera beçala aitcinerat igortceco. Hunec cer iragaiten den, cer beguitarte içaiten duen, eta nor nola mintço den, avisu eman diaçadan. Guero avisu haren arauaz, ethorquiçunerat governatceco : Eta bi garren partearen camporat atheratceco, edo barrenean guelditceco eta estaltceco."

(Gero, 1643, 16. or.)

Idazten zuelarik pasarte hori - noiz ez dakigu - gogoan zaukan Axularrek bi parte izanen zirela, bainan entsegu gisa lehenbizikoa bakarrik agertuko zuela eta ikusirik arrakastarik ukanen zuen ala ez, orduan, menturaz, kanpora aterako zuela edo barrenean geldituko eta estaliko.

Azkenean, zer egin duen ez dakigu eta hori izan da zenbaiten galdea : agertu den liburuak bi parte dauzka ala bat bakarrik? Hauxe da ere Patxi Salaberri Muñoa-ren kezka. Berrikitan (1998, 241-271. or.), "Gero liburuaren koherentziaz eta egituraketaz" idatzi duen artikulu mamitsuan aipatzen ditu bera baino lehen Gero-ren egituraz arduratu direnak, hala nola Julio de Urkijo, Intxauspe kalonjea eta Lafitte kalonjea.

1864-ean, Intxauspe-k argitaratu zuelarik Gero-ren edizioa, zion aitzin solasean :

"Badirudi Axularen guthun edo paperac emanac içan cirela imprimaçailleari ondozcatu gabe, ordenan eçarri gabe : eta hunec imprimatu dituela albeçala, escuen artean guerthatcen citçaizcan ereduraz, lehena azquen, azquena lehen : etçuelacotz guidariric eta ez chuchençailleric"

(Intxauspe, 1864, VII-VIII. or.)

Zer nahi gisaz Intxauspe-k aurkitzen ditu bi parte eta haren arabera hona nola sailkatzen dituen :

Lehen partea : Gerotiarrak.

I Alferra (1-2 eta 3. kap.)

II Gaztea (13. kap.)

III Zaharra (14. kap.)

IV Hiltzera doana (15. kap.) 


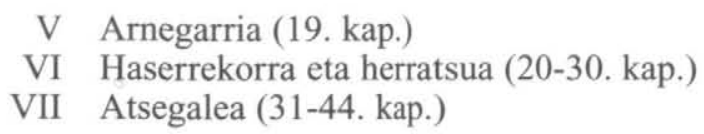

Bigarren partea :

I Gero ez da geurea (4 eta 5. kap.)

II Geroago nekezago (6-8. kap.)

III Bekatuen neurria (9. kap.)

IV Jainkoaren atsekabea (53. kap.)

V Aingeruen atsekabea (54. kap.)

VI Guztien atsekabea (55. kap.)

VII Kontzientziaren aladura (45. kap.)

VIII Obra onen galtzea (16-18. kap.)

IX Denboraren galtzea (12. kap.)

X Jainkoaren miserikordia (10 eta 11. kap.)

XI Jainkoaren justizia (56-60. kap.)

XII Bertutearen erraztasuna (48-50. kap.)

XII Bertuteak dakarkeen bakea (46. kap.)

Azkentza :

I Behar dela konfesatu (51 eta 52. kap.)

II Behar dela on iraun edo pertseberatu (47. kap.)

(Lapurdum III, 1998, 243-244. or.)

Ohar gaitezen Intxauspe-rentzat lehen partea doala lehen kapitulutik 44. kapitulura, kenduz hamabi kapitulu bi multzotan : lehena 4.etik 9.era, bigarrena aski nahasia, bilduz 16.-18. kapituluak, gehituz 12. eta 10. eta 11.nak eta 45 . kapitulutik hasirik bertze guziak sartzen dira, aski nahasirik, bigarren partean eta azkentzan.

Lafitte-k, Intxauspe-k bezala pentsatzen du bi parte dauzkala Gero liburuak eta osoki nahasiak direla kapituluak (1956, 341-344. or.) :

"Liburua irakurtuz aise ageri ditake nor-nahiri, kapitulu guziak ez direla behar luketen lekuan. Nola behar litazken ondozkatu eta elgarri jarrik-arazi, ez da argi ere. Inchauspe zenak bere gisako segida batean ezarri zituen, bainan bertze arrimurik asma ditake.

Gure iduriko lehen parte batean Axular-ek erakusten dauku zertako ez den luzamendutan ibili behar :

Lehenik, geroko uzten duen konbertsionea mentura tcharrean delakotz; alabainan geroa ez da gure eskuko, geroago eta nekezago da onerat itzultzea;

Bigarrenekorik, bekatuen egoiteak dohakabe uzten gaitu : alabainan bihotza doluminez dauka bekatoreak; bekatuan higatu denbora galdua du; eternitatea galtzen du; $e z$ du ezagutzen bertutearen gozorik.

Zathi hortan jalgi ditaken chedea : kofesatu behar dela eta ongian iraun.

Bigarren zathian chehe-chehea ikertzen ditu lau bekatu nausi : alferkeria, zin egiteko usaia, hasarrea eta lohikeria.

Bakotchaz erraiten du nolako ondorioak dituen eta nola ditaiken garait.

Itchuren arabara Axular-ek bere lana bururatu balu, bertze jaidura gaichtoak ere jorratuko zituen - behinik behin, gezurra eta ohointza - eta naski bertuteak ere goretsiko."

(Gure Herria, 1956, 342-343. or.)

Egiazko iraultzan sartzen da Lafitte. 
Alabainan, bigarren partean ezartzen ditu bekatu nausiak : alferkeria (1-3. kap.), zin egiteko usaia (19. kap.), hasarrea (20-30. kap.) eta lohikeria (31-44. kap.), bertze kapitulu guziak lehen partea osatzen dutela.

Iritzi berekoak dira Intxauspe eta Lafitte, lehenak aipatzen duelarik "cerbait nahasteca" eta bertzeak diolarik "kapitulu guziak ez direla behar luketen lekuan", nahiz biek ezartzen dituzten bekatu larriak parte batean, Intxauspe-k lehen partean, Lafitte-k bigarrenean.

Ez da, aldiz, batere iritzi hortakoa Aita Villasante. Harentzat ez dira agertzen bi parteak, bat bakarrik agertzen da. Hona zer dion :

"De hecho nunca apareció más que la primera parte, no por falta de éxito seguramente, sino porque la muerte del autor siguió de cerca a la aparición de esta primera parte (si ya no es que había muerto antes de que apareciera el libro). Por eso vemos que cuando años más tarde, en fecha que no podemos precisar, se publicó la segunda edición de la obra, se quitó del título la mención de las dos partes."

(Historia de la literatura vasca, 76. or.)

Patxi Altuna Aita Villasanteren ildotik doa, Axular-i buruz idatzi duen artikulu batean :

"Nuestra opinión personal es que no abundan en modo alguno en la obra los pensamientos propios de la segunda etapa, los de la perfección, cuando resulta que casi al final de la misma en los capitulos 53-55 se nos insta todavia a no aplazar y demorar la conversión, porque con ello se está cometiendo una injusticia contra Dios, contra los ángeles y contra todos los seres del universo, en clara disonancia con lo anunciado en el subtítulo de la obra como contenido de la segunda parte : aplicar uno a su deber "dejados los aplazamientos" sin acabar nunca de dejarlos. Lo que tenemos es, pues, sólo la primera parte, pero en un estado de claro y lamentable desorden por lo que a la secuencia de los capitulos se refiere."

(Los escritores. Hitos de la literatura clásica euskérica, 1996, 199. or.)

Horretan ginauden Patxi Salaberri Muñoa jin baino lehen; bere tesian - oraindik ez argitaratua - eta aipatu dudan Lapurdum III-ko artikuluan azaltzen digu bere ikus-moldea.

Labur bilduz, Patxi Salaberri Muñoa-ren iritzia da Gero-k, den bezala, baduela bere koherentzia eta logika tematikoa. Linealtasuna aurkitzen du lehen kapitulutik azkeneraino.

Beraz, Intxauspe eta Lafitte-ren teorien kontra doa. Gero-k badu bere batasuna eta hona nola ikusten duen barneko egitura.

I-XV. kap. : Konbertsioaren atzeratzea, denbora galtzea faktorearekin loturik agertuko da.

XV-XVIII. kap. : Konbertsio prozesurako lehen urratsak : borondatezko obrak eta obligazioak.

XIX-XIV, kap. : Bekatu buruzagi zenbaiten kalteak eta haien aurkako erremedioak (kolera, haragia eta abar) tratatzen dira.

XLV-XLVII. kap. : Konbertsioaren atzeratzea kontzientzia faktorearekin loturik : kontzientzia gaixtoa $v s$ ona $>$ pertseberatzeko beharra.

XLVIII-L. kap. : Parabisura joatea errazago da infernuratzea baino. 
LI-LV. kap. : Penitentzia (eta haren praxia : konfesioa) ezinbestekoa da; bestela, atzeratzearekin bidegabe egiten zaie guztiei : Jainkoari, aingeruei eta kreatura guztiei.

LVI-LX. kap. : Azkenkien kontsiderazioa, konbertsiorako bidea : infernuaz.

(Lapurdum III, 1998, 257. or.)

Multzo horiek banaturik, azpi multzo batzu ere aztertzen ditu Patxi Salaberri Muñoa-k, eta segidan sakonduz egiten duen azterketan estudiatzen ditu gai-lokailuak eta halaber kapituluen barne-egiturak (sermoi-egitura, hasierak eta amaierak). Koherentzia eta linealtasuna ongi erakutsirik Axular-en obran ez du halere ikusten non dauden delako bi parte horiek, diolarik :

"Airean geratzen da, dena dela, obra bi parteetan eman nahi izanaren arazoa. Izan ere, bestelako elementurik (lekukotasun historikoak, testuak, etab.) ez den bitartean, badirudi nekez aurki daitekeela liburuan bertan argitzaile izan litekeen aztarnarik."

(Lapurdum III, 1998, 268. or.)

Derradan berehala ez naizela batere ados Intxauspe eta Lafitte-ren iritziekin aipatzen dutelarik "nahasteca" edo "kapituluak beren lekuan ez izaitea" eta, aldiz, ni ere Patxi Salaberri Muñoarekin nagoela hatzemaiteko Gero liburuan egiazko koherentzia eta logika. Halere ez da dudarik enetzat bi parte aurki daitezkela liburuan bertan eta badirela argitzaile diren aztarnak.

\section{Lehen partea (I-XLIV)}

Liburuaren titulua irakurtzen delarik argi errana da bi parte badirela eta lehenaren nola bigarrenaren edukina agertzen da. Hona lehen partearena :

\footnotetext{
"Lehenbicicoan emaitenda, aditcera, cenbat calte eguiten duen luçamendutan ibiltceac, eguitecoen gueroco utzteac."
}

Esaldi horretan azpimarratzen ditut zenbait hitz : calte, luçamendu, gueroco, horiek direlakotz enetzat hitz-gakoak. Kalteak dira ondorioak, ondorio gaixtoak, luzamendutan ibiltzeak dakartzanak. Lehenbiziko parte horretan sartuko dira bekatu larriak, hain zuzen Axular-ek hautatu dituenak, denboraren iragaitearekin lotzen dituenak. Beraz lehenbiziko partea doa lehen kapitulutik 44.a arte.

Bekatu nagusiena alferkeria da, denetan lanjerosena. Hortakotz lehen kapituluak, alferkeriatik ihes egiteko lanaren edo "trabaillu"-aren merezimenduak aldarrikatzen ditu. Erlearen eta xinaurriaren ereduak ongi hautatuak dira eta bukatzen dute kapitulua erakutsiz zer den lanaren beharra alferkerian ez erortzeko.

Bigarren kapituluak, aldiz, argi eta garbi salatzen du zer den alferkeria eta hain zuzen lehen aldikotz agertuko da kalte hitza kapituluaren tituluan :

"Cenbat calte eguiten duen alferqueriac; eta nola handic sortçen den guerotic guerora ibiltcea."

Pasarte labur batean emaiten du alferkeriaren definizioa. Latinetik hartu etsenplu batetik hauxe dio :

"Alfertasuna da erguelquerien ama, eta vertutèn ugaz ama."

Itzulpen horren ondotik segitzen du :

"Eta halatan erguelqueriec, erhoqueriec eta vicio suerte guztiec eguiten dute laster alfer- 
tasunera, ceren ama baitute; baiña verthutèc eta obra onèc, ihes. Ceren nola baitute ugaçama, baitaquite, eztuquetela haren ganic, beguitarteric, eta ez ongui ethorriric." (39. or.)

Lerro hauetan Axular-ek baliatzen du ama/ugazama edo amaizunaren aurkaketa hain ezagutua denbora haietan umezurtzen artean, errepikatua ere atsotitzetan, hiru segidan emaiten dituela Oihenart-ek egin duen bilduman.

22. Ama sinets eztezanak, amaizuna.

23. Amaizuna erradan : no, ez, nahiduna.

24. Amaizuna, eztizkoa ere, ezta huna.

Bainan alferkeriak, bizio guzien amak, nagikeriaren ahizpak, kalte ikaragarriak dakartza : pobrezia, errumeskeria eta bertze. Kapituluaren tituluan salatzen zuena, kalterik handiena, ondoriorik latzena da gerotik gerora ibiltzea.

"Baiña calte guztien gaiñeco caltea, alferqueriatic heldu den handiena, ceiñi narraicola erran baitut nic, oraiñocoan erran dudan guztia, da luçamendua, guerotic guerora ibiltcea. Ceren nagui-alferrac eztu behin ere erraiten egun, Bethi bihar, bethi guero, bethi luçamendu. Alfertasuna da guero guztien ithur-burua, cimendua eta ama; eguiteco guztiac egunetic biharrera, presentetic ethorquiçunera, eta guerotic guerora luçatcen dituena. Eta ama hunen alaba haur, naguitasunetic eta alferqueriatic sortcen den, guero haur, da gure galgarria, gure içurria, eta egun daiñotic gure etsai deabruac gure enganatceco ediren ahal duen bideric eta arteric hoberena, finena eta segurena." (44-45. or.)

Hemendik goiti, hirugarren kapitulutik hasiz, aztertzen du Axular-ek zer den luzamendua, zer den, bereziki, denboraren iragaitea eta zer kalte dakarren. Harturik etsenplutzat San Agustinek dioena bere "Kofesioetan", nola utzi zuen denbora iragaitera eta nola luzaz luzamendutan egonik deliberatu zuen, azkenean, epetan ez gehiago ibiltzea, Axular-ek erakusten du ez dela hori gure erabakia :

"Baiña guc eztugu hala eguiten, egunetic egunera gabiltça, bethi prometa, bethi gogo har; ; ta behin ere ez ethen, behin ere ez delibera, eta ez compli : bethi nahi, bethi nagui, nahicunde hutsetan, desircundetan, denbora guztia gal, eta hala gaudecilla, heriotceac atrapa, atceman eta har." (53-54, or.)

Luzamenduaren ildotik joanez, geroaren segurantzarik ez dela dio Axular-ek. Gauza segura heriotzea eztakigularik ez eguna, eta orena. Ez dela geroko segurantzarik kontutan hartu behar luke bizi denak eta gogoan atxiki sortzen garenean hasten garela hiltzen.

Denbora neurtzen ez dakiten jendeek nahiago dute orainean bizi, oraina gozatu utziz gerorako egiazko urrikia :

“... gueure bicitcearè ere iaun, iabe eta nabusi baiquina beçala, ordenatcen dugu bicitcearen parte bat, eta parteric hoberena eta gaiena, gaztetasuna, munduarentçat, eta guero gaiñeracoa, gaixtoena, çahartasuna, Iaincoarentçat." (66. or.)

V. kapituluarekin bukatuko du Axular-ek lehen azpi multzoa denborari eta bereziki iragaiten den denborari eskainia, bentura hitza erabiliz bere erran-nahi guzietan. Kapituluaren tituluak salatzen du nola dabilan Axular hitz-jokoekin :

"Nola gueroco venturaren venturan, venturaturic galtcen garen." (68. or.)

Bentura delako horretan sartua da mundua geroko segurantzarik ez duelarik. Ez daki giristinoak nora doan; mundu honetan benturaturik dago, utziz gerorako egin behar dituenak. Hortakotz, horiek guziak ikusirik, amaitzen du kapitulua Axular-ek aholku bat emanez : 
"Ez caitecilla beraz gu ere guerocoan fida. Ceren gueroco hartan, ventura bat ahal badateque ere, ez ordea segurantçaric; eta erhoqueria handia da segur beharduen gauçaren venturan ibentcea : biharamuneco esperantçan eta perilean utztea." (77. or.)

Bigarren azpi multzoak besarkatzen ditu lau kapitulu, 6.tik 9.ra. Luzamenduak dakartzan kalteak aipatzen dira. Kapituluen tituluek ongi adierazten dute zer diren ondorio gaixtoak :

VI. Nola den gueroago gaitzago beccatutic ilquitcea.

VII. Nola guerotic guerora ibiltceaz coberatzen den usanţ̧a gaixtoa.

VIII. Nola usanţ̧a gaixtoac gogortcen eta ezansiatcen duen beccatorea.

IX. Nola guerotic guerora gabiltçala bethaditequeyen beccatuen neurria eta ossa contua.

Lau kapituluen arteko lokarria nabari da. Bekatuan sartua dena bekatuan gozatzen da. Ardi errebelatuaren pare gero eta galtzenago eta aztura gaixtoetan sartzenago da. Gaztetan hartu pleguak eta azturak gogortzen dira denborarekin, itsumendua nagusitzen baita eta jendeari gero eta atseginago baitzaio bekatuan egoitea. Bekatuen kontuak bukatzen du azpi multzoa.

Jainkoak, denen berri jakinez, hartzen du pazientzia bekatorearekin; uzten dio askatasuna bainan bada muga bat, kontu bat. Muga hori iraganik, kontua beterik ez da gehiago barkamendurik eta, beraz, Jainkoaren miserikordiaren ardiesteko, behar da neurri bat atxiki.

Hain zuzen, hirugarren azpi-multzoaren gai nagusia da Jainkoaren miserikordia.

Sei kapitulu biltzen ditu Axular-ek gai horren inguruan. (X., XI., XII., XIII., XIV., XV.)

Jainkoaren miserikordian behar da fidatu. Ez da giristinorik Jainkoaren baitan fida ez denik. Lekuko dira mirakuluak : Jonas, Israelgo semeak itsasoa iragaitean, Susana, Daniel eta bertze... Bainan fidantzia ez zaio faltatu behar bekatoreari. (X)

Denbora berean Jainkoaren miserikordiaren lortzeko bakoitzak behar du berea eman, miserikordiak eta justiziak pisu berdina dutelakotz balantzan. Miserikordiak pisu gehiago ukan dezan gaztigatu behar da bekatua eta penitentzian sartu berehala eta ez geroko utzi behar. (XI)

Geroko uztea denbora galtzea da eta Axular-en iritziz denbora galtzen da bekatu eginez eta bekatuan egonez, gogoeta ero, bano, deus balio ez duten batzuetan egonez, gorputzaren plazeretan ibiliz. (XII)

Bertze hiru kapituluetan Axular-ek aztertzen ditu hiru kasu ezagunak :

XIII. "Gaztetic çahartcera penitencia luçatcen duenaz.” Egia da gazteak nahi duela bizia preziatu eta gerotik gerora ibiliko dela, pentsatuz astia baduela konbertitzeko.

XIV. "Çahartcean ere penitenciaric eguiten eztuenaz." Bihotza gogortua, itsutua ere ez du zaharrak Jainkoaren deirik entzuten. Bekatuan sartua eta ez da gehiago mirakuilurik, ez urrikitan sartzerik.

XV. "Heriotceco oreneraiño beccatutan egon gogo duenaz." Hau da azken kasua, kristorekin batean gurutzetua izan zen ohoin batena "ohoin onarena", azken mementoan urrikitu zena. Hori ez eginez bakoitzak galtzen du bere burua.

Azkenean, alferkeriaren kalteek, luzamendutan denbora galtzeak giristinoa deramate bekatuan murgiltzera, penitentziari uko egitera, bere buruaren galtzera, 
heriotzeko orenean ez denean konbertitzen. Ez dezagula ahantz "Gero"-ren tituluan Axular-ek aurkezten duela Ecclesiastikoak dioena : "Ne tardes converti ad Dominum et ne differas de die in diem."

Leize hortarik ateratzeko ba ote da erremediorik?

Hiru kapitulutan Axular-ek aditzera emaiten du zer den erremusinaren eragina.

XVI. "Erremusina eguiteaz, eta handia sortcen den probetchuaz." Titulu horren pean aztertuak dira aberatsen eta pobreen arteko harremanak, zein beharrezkoa den aberatsarentzat pobrearen alde jokatzea zeruko loriaren ardiesteko.

Bertze bi kapituluak, lehenaren emendio gisa sartzen dira Axular-ek duen helburuan : gerotik gerora ez ibiltzea, obra onak ez eginez bizi deno, utziz lana ondokoentzat edo berdin bakoitzak dituen zorrak ordaintzea lehen bai lehen, ondokoetara utzi gabe.

Lehenbiziko hemezortzi kapituluetan alferkeriaren edo ezazolkeriaren kalteak eta ondorioak Axular-ek aztertu ditu. Bertze bekatu mota batzuetan sartuko da orain : juramentua, kolera eta etsaigoa, haragia.

Hemendik goiti hiru bekatu horien kalteak eta kontra egiteko dauden erremedioak azalduko eta ikertuko ditu, erakutsiz, alde batetik, zer ondorio txarrak dauzkan bekatuak eta, bertze aldetik, erakutsiz zer bide nasaiak diren bekatuaren aurka jokatzeko eta bizi onaren eremaiteko.

Juramentuak kapitulu bakarra dauka.

XIX. "Cenbak calte eguiten duen iuramentuac eta iuramentu eguiteco usantçac eta nola behar den lehen baiño lehen usantça hura utci."

Juramentua gezurrari lotua zaio eta bekatu larria da zin egitea, Jainkoa lekuko hartzen baita orduan. Lehenik agertzen balinbada bekatu larrietan da, hain zuzen, Jainkoa gezurraren lekuko hartzen duelakotz. Hala dio, argi eta garbi Axular-ek :

"Gueçurrez iuramentu baten eguitea, munduac hala ezpadaduca ere, beccatu handiagoa, lagunaren onaren ebastea baiño, eta bai edo cein emazterequin parte içaitea baiño ere, ceren iuramentuac, Iaincoa bera bere presunan utquitcen du, baiña bertce beccatu hauc, eztiote hain arras emaiten, etçaitça hala hurbiltcen." (254. or.)

Juramentu egitearen usantza da ifernuko bidean sartzea, bidegabe handienetarik egiten baitzaio Jainkoari. Jakinik gauza desohorezkoa eta desohoragarria dela juramentua, badira usantzaren kontra jokatzeko Axular-ek aurkezten dituen erremedioak : gogo eta borondate fin bat bekatu hortan ez erortzeko, mihia behar den bezala atxikitzea, ñabardura guziak emanez erraiten direnetan, Jainkoa lekuko hartzearen beharretan ez izaiteko.

Bigarren bekatu larria kolera eta ahaide duen etsaigoa doatzi XX. kapitulutik XXX. araino, hameka kapitulu orotara. Nabari da bekatu hori barreatua zela Euskal Herrian.

Hemen ere XX. kapitulua hasten da formula berarekin :

"Cenbat calte eguiten duten colerac eta etsaigoac eta nola behar den lehen baiño lehen etsaigoatic campora." 
Kalteak agertzen dira lehenbiziko kapituluan ikusiz nola haserretzen delarik bertze norbaiten kontra eta ez balinbada berehala baketzen, gero eta gaitzago izanen dela bake egitea.

Denbora pasa, luzamendutan egoitea da gogortzea bai hasarrean eta bai etsaigoan. Pentsa dezala bat bederak haserre denean ez dela batere bere baitan, bai aldiz deabruaren meneko :

"Ceren iaquiçu ecen cerori ere haserre çarenean, hala çarela, erho çarela, itsu çarela, hordi bat beçala irrigarri çarela." (281. or.)

Gero agertzen dira koleraren kontrako erremedioak :

1- kondizino haserrekorrari begiaren edukitzeat (XXI)

2- dirakien eltzeari egiten zaikana kolerari ere egitea (XXII)

3- lehiatzea kolera iragan arteiño pausatzea (XXIII)

4- kontsideratzea etsaiek egiten derauzkiguten bidegabeak Jainkoaren gaztiguak direla (XXIV)

5- kontsideratzea zer moldez dagoen zure etsaia haserre denean (XXV)

6- ez bilatzea zer dioten gutzaz jendeek (XXVI)

7- eta azkenik bertze erremedioak (XXVII)

Denetarik bada : bere buruaren jabe izaitea, lasaitasunean egoitea, bakoitzak bere baitan obra dezakeena eta gero, etsaiaren aldetik edo gizartearen aldetik heldu direnak. Orotara, orduko giristino morala eskaintzen du Axular-ek.

Bertze hiru kapitulu laburretan (XXVIII., XXIX. eta XXX.) Axular etsaigoaz mintzo da eta bereziki nola behar zaion barkatu etsaiari eta nola behar den maitatu.

Jainkoak hala manatzen baitu : ongiaz gaizkia garaitu behar da. Dena Jainkoaren eskuetan dago, mendekatzea ere ez baitio utzi nahi bat bederari mendekatzeko parada.

Eta, egun batez, nahi bada Jainkoaren barkamendua ardietsi, behar zaio barkatu etsaiari eta hori, lehen baino lehen, geroko luzatu gabe.

Nahiz Axular-ek idatzi duen gezurrez juramentu baten egitea bekatu handiagoa dela edozein emazterekin parte izaitea baino, iduri luke halere, ikusiz zer garapen emaiten dion haserre eta etsaigoari (hameka kapitulu) haragiaren bekatua denetan handienarik bat dela hamalau kapitulutan garatua baita. Jadanik derabilan egitura baliatuko du, aztertuz lehenik zein diren kalteak eta gero nolako erremedioak on diren bekatuan ez erortzeko. Kalteak ugari dira flako delakotz haragia.

Lehenik amore desordenatuak itsutzen du gizona emaztearen mutil eta azpiko jarriz. Labur bildu du Axular-ek gizonaren menpetasuna erran trinko famatu batean :

"Amorantea cen nabusi : no cen tho, emaztea guiçon, oilloa oillar," (343. or.)

Bigarren kalteak dakar mugarik ez duela ezagutzen ahaikoarik hurkoena ere ez, hala nola Neron bere amarekin, Henriko Ingalaterrako erregea bere alaba bastartarekin. Orduan sortzen da hirugarren kaltea, arnegutan, juramentutan, faltsukerian eta gezurrean erortzea daukan gutiziaren gozatzeko.

Gehiago dena, laugarren kaltearen eragina da maitasunari nausitzen zaiola bortizkeria, bakeari gerla eta bosgarrenarekin galtzen dela osoki sosegua eta 
beharrezkoa den pausua. Orotara bortz kalte garrantzitsuak bertzelakotzen dituztela jendeak eta gizartea, alde batera utziz Axular-ek eta orduko moralak erakasten duena : gizona dela ordenatua emaztearen jaun eta nabusi izaiteko, ez duela hautsi behar ezkontzaren legea, are gehiago apezak garbi egoiteko egin duen botua, denak mundu baketsu eta giristino batean ongi bizitzeko.

Nasaiki azalduak dira beharrezko erremedioak hamar kapitulutan eskainiak : otoitza lehenik, gogoeta lizunak ez onartzea, prestu izaiteko nahia, ez alfer egoitea, ikustea zein laburra den haragiaren plazera eta zein ondorio gaixtoak uzten dituen, bortz sentsuak kontutan hartzea, begiak eta mihia bereziki, sabelari ez sobera emaitea. Debekuak heldu dira gero hala nola dantza, banalorian ez erortzea, usain onez beterik ez ibiltzea eta bereziki ukitzetik urruntzea, hau delarik bekatu sortzailerik handiena bortz sentsuetan :

"Iccusteaz, mintçatceaz, ençuteaz eta usnatceaz eguiten da beccatu, ez ordea uquitceaz beçala." (417. or.)

Beraz erremedioak eta debekuak ongi hartuz eta, gerotik gerora ibili gabe, kontsideratuz erremedio handiena Jainkoa beha dagokula, garaituko da etsairik perilosena dena, haragia bere kalte guziekin.

XLIV. kapituluan bururatzen da Gero-ren lehen partea, alferkeriak, juramentuak, haserreak eta haragiak sortzen dituzten kalteak azaltzen dituena eta erremediatzeko bideak ere.

\section{Bigarren partea (XLV-LX)} rekin.

Bigarren partea, ikusten den bezala, aski laburra da konparatuz lehen partea-

Hamasei kapituluk osatzen dute bigarren partea, bainan ez da dudarik bien arteko muga XLV. kapituluan dagoela.

Oroit gaiten zer dion Axular-ek Gero-ren titulu orokorrean :

"Bigarrenean quidatcen da eta aitcinatcen, luçamenduac utciric, bere hala, bere eguin bideari lothu nahi çaicana."

Hemen, lehen parteko tituluan bezala, azpimarratuko ditut zenbait hitz Axular-ek daukan helburua salatzen dutelakotz: hauek dira "quidatcen", "aitcinatcen", "utciric" eta "eguinbidea". Zinez, kalteak eta erremedioak utzirik bertze bide bati lotzen zaio Axular, salbamenduko bideari bi aditzek kidatu eta aitzinatu adierazten duten bezala.

Alta, deus ez da ezagun kapituluaren tituluan :

"Nola guerotic guerora gabilţ̧an bitartean, alha çaicun concientcia gaixtoa."

Egia da luzamendutan dabilalarik, zerbait, bere barrenean, sortzen ari zaiola eta hori da kontzientzia, ongia eta gaizkia bereizten dituena.

Bertzalde, kapituluaren lehen lerroak irakurri-eta, ikusten da zeri buruz ari den Axular, bigarren partearen tituluak dauzkan hitz-gako berak edo bertsuak baliatzen baititu.

"Badu gutaric bat bederac, bere baithan barrena, Iaincoac emanicaco aitcindari bat, quidari bat eta argui eguille bat. Eta harc eracusten deracu cer dagocun ongui eta 
cer gaizqui : noiz goacin maccur eta noiz artez. Eta are guehiago harc berac bere ahal guztiaz aitcinatcen eta bulccatcen gaitu ongui eguitera eta guibelatcen, eta hastantcen gaizqui eguitetic." (419-420. or.)

Aitzindari, kidari, argi egile gisa agertzen da gu baitan daukagun kontzientzia. Hiru kapitulutan garatuko du Axular-ek, aztertuz zer den kontzientzia gaixtoa eta zer kontzientzia ona eta nola behar den iraun eta pertseberatzen entseiatu. (XLVXLVI-XLVII)

Gero-ren lehen kapituluan aipatua da nola Jainkoak sortu zuen mundua eta bereziki gizona, batere bekaturik eta bekaturen kutsurik gabe; bigarren partearen hastapenetan aipatua da ere nola, hastetik egin zuenetik beretik, eman zion Jainkoak gizonari lege naturala, lege naturala delarik bat bederaren kontzientzia. Markatzen du Axular-ek zer diferentzia den kontzientzia onaren eta gaixtoaren artean diolarik :

"Concientcia batçuc dira erne, senticor, minbera, hertsi : eta berriz bertce batçuc, loti, hil, laço, çabal eta ez antsia." (425. or.)

Kontzientzia, kidari eta argi egile izanez lehiatzen da "lehen baiño lehen, gueroco luçamendutan ibili gabe" (440. or.), bide onean jartzea giristinoa.

Zer nahi gisaz lanjerrak hor daude gure zain, lerratzeko bidean. Bainan bekatuek gerla eta kalteak sortzen balinbadituzte, kontzientzia onak, aldiz, sortzen du bakea eta sosegua. Hortakotz bide onean ezarri nahian giristinoa, dio Axular-ek XLVI. kapitulua bukatzean :

"Bada verthuteac, prestuqui bicitceac, bertce pagamenduric eta golardoaric ez palu ere, concientcia onaren baquea eta sosegua baicen ere, hargatic beragatic ere behar guenduque, lehen baiño lehen, guerotic guerora ibili gabe, egunetic biharrera luçatu gabe, orai berean, concientcia onaren, ontasun handi hunen erdiestera enseiatu eta lehiatu." (453. or.)

Bide onean sarturik kontzientzia onari esker, behar da iraun eta pertsebatzera entseiatu. hau da XLVII. kapituluaren gaia. Xeheki aztertzen ditu Axular-ek bi pertseberatze-moldeak eta bi iraute-suerteak. Haiei jarraikiz dio deplauki kapituluaren bukaeran :

"Fineraino eta finean perseveratcen duena içanen da salbatua, eta ongui çortheatua." (473. or.)

Esperantzaz beteriko hitzekin amaitzen du :

"Ceren halatan erdietsico dugu orai perseverantciaren donua, eta guero, azquen finean arimen salbamendua, seculaco loria." (473. or.)

Hiru kapitulu bakarrik, bainan mamitsuak eta luzeak lehenak sarrera eta zazpi azpi-kapitulu, bigarrenak sarrera eta lau azpi-kapitulu, hirugarrenak sarrera eta bortz azpi-kapitulu dituztelarik. Ageri dago sail honen balio handia Axular-entzat.

Bigarren sailean parekatuak dira giristinoak har ditzazken bi bideak, ifernukoa eta parabisukoa. Axular-i iduritzen zaio gaitzagoa dela ifernuko bidea. Nahiz hanitzek dioten parabisuko atea hertsia dela eta harat heltzeko bidea meharra, hala ere entseatuko da frogatzera errazago dela ifernukoa baino.

XLIX. kapituluaren titulua da "Nola parabisuco bidea den erraz". Kontsideratu behar dira Jainkoaren laguntza, etorkizuneko esperantza; giristinoaren gogoa geroari buruz itzuli behar da eta ez atxiki eguneroko harremanetan. 
Laborariak fruituen esperantzan aise iragaiten du lur-lanetako nekea. Jainkoaren laguntzari esker, leguntzen da bidea, zabaltzen, giristinoak daukan karga arintzen da, borondatez eta amorioz, jasaiten balinbada.

"Eta hala segur da, parabisuco bidea, behar den bidean hartcen duenarenţ̧at, plaun dela, erraz, placent eta atseguin." (498. or.)

Hori frogatuz gero erakusten du Axular-ek L. kapituluan errazago dela parabisuko bidea ifernukoa baino. Azkenean, etsenplu asko emanik, hala nola zenbat lan duen ohoinak bere ohoinkeriaren egiteko, gezurtiak zenbat gezur eta hitz eder behar dituen asmatu bere gezurraren sakatzeko eta egiatzat saltzeko, ifernuko bidea ez dirudi hain erraza. Aldiz, zama eta karga ukanagatik mundu honetan, Jainkoaren zerbitzariek kontsideratzen dute bertutearen zama arinago dela bekatuaren karga baino, Jainkoaren graziari esker.

Bi bideak balantzan ezarririk, dio Axular-ek segur dela "parabisuco bidea erraçago dela ifernucoa baiño eta ifernuratcen denac pena eta trabaillu guehiago iragan behar duela ifernuratceco, ezen ez parabisuratcen denak parabisuratceco." (522. or.)

Kontzientzia argitua, parabisuko bidea errezagoa delarik, nola sar parabisuko bide honetan ez balinbada kofesioaren bitartez.

LI. kapituluarekin hasten da bertze sail bat. Beharrezkoa da kofesioa, arimako eritasuna sendatzen baitu, bekatua delarik arimaren zauria. Nahiz Elizak hala manatzen duen, ez da aski urtean behin kofesatzea, maiz kofesatzen delarik handik heldu diren probetxuak nabari direla (LII. kapitulua). Ez ahantz purgatorioko penak laburtzen direla eta bekatuan eroriz gero, hobe dela lehen bai lehen kofesatzea. Barkamendua erdietsirik, indar gehiagorekin lotzen zaio lanari giristinoa eta gerotik gerora, egunetik biharrera luzatu gabe, Jainkoarekilako elgarrizketaren bitartez "azquen finean erdietsico du bere arimaren salbamendua." (548. or.)

Ohar bedi giristinoa, gerotik gerora, luzamendutan egonez eta ez kofesatuz bidegabea egiten diola Jainkoari. Alabainan gehiago estimatzen du Jainkoak penitentzia egiten duen bekatorea penitentziaren premiarik ez duen justua baino, ardi errebelatua, haur prodigoa, Magdalena eta Jondoni Paulo lekuko. (LIII)

Ez bakarrik Jainkoari, bainan aingeruei ere egiten die bidegabea gerotik gerora dabilanak (LIV), haien artean aingeru begiralea deritzanak arima bakoitzaren salbamendua desiratzen duela. Arimen laguntzaile honek atsegin hartzen du obra onak egiten direlarik, tristatzen aldiz obra tzarrekin. Entzun beza giristinoak Axular-ek egiten dion gomendioa :

\footnotetext{
"Beraz hunelatan, hargatic beragatic ere, Ainguiruey bai atseguin, baiña damuric eta atsecaberic ez eguiteagatic ere, behar guenduque egun beretic, geroco luçatu gabe, trabu guztiac khenduric, salbamenduco bidea hartu, eta hartan guelditcen çaicun gueure mende appurra, emplegatu." (562. or.)
}

Geure buruari ere eta giristino lagunari ere bidegabe egiten diegu, lehenik guk dugun etsairik handiena geure burua baita eta nola ez lagunarentzat, bai etsenplu txarra emanez eta bai gaixtakeriak eginez. Bekatuan egoiteak bidegabe egiten die kreatura guztiei Jainkoaren bidetik urrunduz. Axular-entzat kofesatzeak eta bereziki maiz kofesatzeak ezartzen du giristinoa bide onean eta, bekatuan ez eroriz edo bederen laster jalgiz, penitentzia eginez, ez die gehiago bidegaberik eginen ez Jainkoari, ez aingeruei eta ez ere giristino lagunei. 
Azken saila, bortz kapitulutan ere banatua da. Gaia da ifernua, gai nagusia Eliza katolikoan azken kontzilioa arte. Ifernua agertzen da ez bakarrik teologian bainan ere literaturan, edergintzan eta bertze.

Bide onean egoiteko giristinoak ifernuko penak kontutan hartu behar ditu. Nahi ala ez, betiereko sua erakusten diote predikariek beldurra sar-araziz bihotzean. Beldurra, izialdura izan dira, luzaz, Elizaren pedagogia, lege zaharreko Jainko mendekatzailea dela lekuko. Axular-ek segitzen du bide klasiko hori :

"Haur da eguia : eta hauc dira, gueure Iaungoicoac aitcinetic eguiten derauzquigun mehatchuac, kheiñadurac, eta bere predicariez emaiten derauzquigun avisuac, hauquin batean, ici gaitecin, iccara gaitecin, eta iccaraturic, guero eguinen dugula diogun ontasuna, presenteon daguigun amoreac gatic." (572-573. or.)

Pentsa dezala bekatoreak ifernuko penetarik handiena dela Jainkoaren ez ikustea, haren konpañiatik eta adiskidetasunik sekulakotzat kanpoan gelditzea. (LVI. kapitulua).

Bada bertze penarik eta gaztigurik, bada "poena sensus" deritzana, sentsuaren pena, su eternala, akabatuko ez dena. Sua, Jainkoak berak piztua, izanen da hemengo sua baino beroago, goriago. Gure sentsu guziak penetan sartuko dira, bista, entzutea, usna, gustua, ukitzea, denek pairatuko dute, dena oinaze eta dolore izanen delarik. (LVII. kapitulua).

Dante olerkariak ikusi zuen ifernuko ate gainean idatzirik : hemen sartzen denak gal beza osoki esperantza. Ez du bertzerik erraiten Axular-ek LVIII. kapituluan : "Nola ifernuan daudenec eztuten handik ilquitceco esperanţ̧aric".

Ikusirik zer diren ifernuko penak, zein garratzak diren eta urteak milaka iragaiten direla, asma daiteke, eta hala egiten du Axular-ek, ifernuan dauden bekatoreek galdegiten diotela Jainkoari, hanbat denbora ifernuan egonik, noiz hortik aterako diren. Jainkoaren ihardespena ikaragarria da :

"Iaquin behar duçue ecen cuen penac eta doloreac, oraiño orai hasten direla : eta hemendic bertze, horrein bertze urtheren buruan ere, orobat, orduan hasiko direla. Gal eçaçue gal, hortic ilquitceco esperanţ̧a. Ceren secula fin gabecotçat hor egon behar duçue". (606. or.)

Elizaren doktrinari jarraikitzen zaio Axular.

Ifernuaren gaiak bertze pentsamenduak sortzen ditu. Kontsidera beza bekatoreak denbora laburrean egin dezakela bekatua eta bekatuaren ondorioa izan daitekela gaztigu handia, luzea, sekulakoa (LIX. kapitulua). Alde batetik gozamen edo plazer apurra eta bertzetik pena edo gaztigu betierekoa. Badaki giristinoak beharko duela egun batez Jainkoaren aitzinean agertu eta justuki jujatua izanen dela. Ez pentsa, halere denak beltz direla.

Ifernutik jalgitzeko esperantzarik ez balinbada, gelditzen da salbatzeko esperantza. Hala dio Axular-ek LIX. kapituluaren azken lerroetan.

"Beraz, arraçoiñequin, guelditcen den ondoco ondoreagatic, laburzqui eguiten den beccatuari, emaiten çaica gaztigu lucea eta seculacoa.

Eta hala emaiten çaica halaber laburzqui eguiten den obra onari ere, seculaco loria eta pagamendua." (613. or.)

Ifernuko gaiaren bururatzeko Axular-ek aipatzen du "cergatic Iainco misericordiosac demboraren buruan bedere ezterauen ifernuan daudeney barccatcen". 
Nahiz Jainkoaren miserikordia handia den, bada ere justizia, honek ezartzen baititu batzu eskuinean eta bertzeak ezkerrean liburu sainduek dioten bezala.

Egia da Jainkoaren miserikordia handia dela, Ninibetarrak lekuko, Jainkoak mehatxatu zituelarik bainan ez suntsitu. Balia gaiten denboraz eta konbertigaiten : "Dembora duguiño daguigun ongui." (619. or.)

Nahiz azken sail honetan argi eta garbi azaltzen duen Axular-ek zer den ifernua, zer diren han pairatzen diren penak, pena horiek sekulakoak direla eta ifernutik ilkitzeko esperantzarik ez dela, sarraraziz bekatorearen baitan beldurra Elizaren erakaspenei jarraikiz, halere bururatzen du kapitulua eta, denbora berean liburua, esperantzazko solasekin.

Lehenik konbertitzera bultzatzen du bekatorea :

"Etçarela bada cerori ceureţ̧at horrein etsai handia, urrical bequiçu ceure burua. Non tardes converti ad Dominum et ne differas de die in diem. Ezteçaçula berant, ezteçaçula luçat : bihurçaiteci lehen baiño lehen ceure Iaincoa gana : etçabiltçala guerotic guerora, egunetic biharrera." (620. or.)

Giristinoen artzain gisa mintzo da Axular. Betetzen du bere artzain egibidea eta azken hitzetan erakusten du bihotzean daukan esperantza, salbatuak izanen direla Elizaren erakaspenak aditu dituztenak.

"Eta hala eguiten duçula, eta hunen aitcineco capituluetan emançaizquitçun arraçoinac ere contsideratcen ditutçuela, esperantça dut Iaincoa baithan, ongui edirenen çarela ; egun beretic bide onean iarrico, edo iartcera enseiatuco çarela.

Eta halatan mundu hunetaco itsaso hunen, tormenta guztiac iraganic, azquen finean salbamenduco portura, salboric helduco çarela.

Iaincoac hala nahi duela." (621, or.)

Harturik, egin dudan bezala, Gero-ren titulu luzean dauden hitz-gakoak, "calte", "luçamendu", "gueroco utzteac" eta "quidatcen", "aitcinatcen", "luçamenduac utciric", nabari da badirela bi parte, lehena luzeagoa, berrogeita lau kapitulutan banatua, bigarrena, aldiz, laburragoa, hamasei kapitulu dauzkana.

Lehenean aztertzen ditu bekatu larriak eta haien aurka joaiteko dauden erremedioak :

- Alferkeria bizio guzien ama, bere ondorioekin, lazakeria, ezazolkeria, gerotik gerora ibiltzea, geroa ez delarik segurra eta bekatuan murgiltzen eta gogortzen delakotz. (I-IX)

Erremedioak izan daitezke : Jainkoaren miserikordian sinestea, bainan ez da penitentzia utzi behar geroko; erremedioa ere erremusina, pobrearen laguntzea, bainan hori ere ez utziz geroko. (X-XVIII)

- Juramentua bere kalteekin. (XIX)

- Kolera eta etsaigoaren kalteak, kolerari doazkion erremedioak eta etsaiari barkatzeko bideak. (XX-XXX)

- Haragiaren bekatuaren bortz kalteak eta dauden erremedioak. (XXXIXLIV) 
Bigarrenari emanen diot titulu gisa : salbamenduko bidea. Lau azpisail dauzka :

- Kontzientzia gidari eta argi egile eta, orduan ontasunean iraun eta pertseberatu. (XLV-XLVII)

- Bi bidetarik parabisuko bidea errazagoa ifernuko baino. (XLVIII-L)

- Kofesatzea, ikusiz Iainkoari, aingeruei eta bertzei egiten zaizkien bidegabeak. (LI.-LV)

- Ifernuaren betiereko gaztiguaren beldurra. (LVI-LX)

Horiek guziak kontutan harturik hel daiteke salbamenduko portura, hori baita, azkenean Axular-ek agiantzen diona giristinoari, Jainkoa baitan duen esperantzarekin.

Jean HARITSCHELHAR

(UMR 5478, Bordeaux III)

\section{Les deux parties du Gero d'Axular}

Résumé

On s'est longtemps demandé si le Gero d'Axular, tel qu'il a été imprimé en 1643, possédait les deux parties annoncées dans le titre mais mises en doute dans l'adresse au lecteur. Inchauspe au XIX ${ }^{\circ}$ siècle et Lafitte dans la première moitié du $\mathrm{XX}^{\mathrm{e}}$ siècle les ont décelées mais en bouleversant l'ordre des chapitres. Récemment Patxi Salaberri Muñoa a démontré l'unité et la cohérence du texte sans cependant en distinguer les deux parties.

Selon l'hypothèse exprimée dans cet article, la première partie va du début au chapitre XLIV où sont exposés quelques péchés capitaux (paresse, colère, luxure...), leurs conséquences néfastes et les moyens d'y remédier; la seconde partie (XLIV-LX) examine les voies du salut par l'examen de conscience, la confession fréquente et la crainte de l'enfer.

\section{Bibliografia}

Altuna, Patxi, 1996, Los escritores. Hitos de la literatura clásica euskérica, Vitoria-Gasteiz, Ed. Gorka Aulestia, Fundación Sancho el Sabio, 199 or.

Axular, 1643, Guero, Bordele (faksimila : Bilbo, Euskaltzaindia, 1988).

Inchauspe, M., 1864, "Aitcinsolhasa" in Axular : Gueroco guero, 3. edizioa (Inchausperen edizioa).

Lafitte, P., 1956, “Axular'en liburuaz”, Gure Herria XXVIII-6, 341-344.

Salaberri Muñoa, Patxi, 1998, "Gero liburuaren koherentziaz eta egituraketaz", Lapurdum III, 241-271.

Villasante, Luis, 1961, Historia de la literatura vasca, Bilbo, Ed. Sendo. 